\author{
Ewa Gumul \\ Uniwersytet Śląski \\ ewa.gumul@us.edu.pl \\ ORCID: 0000-0003-0859-6067
}

\title{
ROLA BODŹCA PODCZAS \\ RETROSPEKCJI Z PERSPEKTYWY \\ TŁUMACZY SYMULTANICZNYCH
}

DOI: http://dx.doi.org/10.12775/RP.2021.004

Zarys treści: Celem niniejszego artykułu jest zbadanie, w jaki sposób studenci tłumaczenia postrzegają rolę bodźca stymulującego w badaniu z wykorzystaniem metody protokołów retrospektywnych. Opisywane $w$ artykule badania ankietowe są częścią badania eksperymentalnego mającego na celu porównanie wpływu dwóch rodzajów bodźca (transkrypcji tekstu wyjściowego i nagrania tekstu docelowego) na informacyjność werbalizacji, ich obfitość oraz dokładność. Ankieta dotyczyła stopnia trudności przypominania, czynników ułatwiających retrospekcję, przydatności użytego i potencjalnego bodźca oraz stopnia zniekształcenia danych pamięciowych przez bodziec.

Słowa kluczowe: tłumaczenie symultaniczne, protokoły retrospektywne, bodźce stymulujące pamięć, badania ankietowe, badanie procesu przekładu

\section{Wprowadzenie}

Drotokoły retrospektywne to jedna z metod procesualnych używanych w badaniach translatorycznych. Ten rodzaj introspekcji polega na uzyskaniu raportów werbalnych od tłumaczy zaraz po zakończeniu zadania tłumaczeniowego. Ta subiektywna metoda badawcza pierwotnie stosowana w psychologii (Ericsson, Simon 1980, 1993) jest od kilku dekad z powodzeniem wykorzystywana również w przekładoznawstwie (m.in. Ivanova 1999, 2000; Vik-Tuovinen 2002; Napier 2002; Englund Dimitrova, Tiselius 
2009, 2014; Gumul 2012, 2017, 2021; da Silva 2015; Ferreira et al. 2018; Herring, Tiselius 2020). Daje ona możliwość przynajmniej częściowego wglądu $\mathrm{w}$ proces tłumaczenia i jako taka stanowi wartościowe narzędzie w badaniu tego aspektu przekładu. Zalety tej metody, jej ograniczenia oraz etapy procedury badawczej z zastosowaniem protokołów retrospektywnych zostały szczegółowo omówione we wcześniejszych pracach autorki (Gumul 2019, 2020b). W niniejszym artykule ograniczymy się zatem do omówienia roli bodźców stosowanych w celu stymulacji pamięci badanych tłumaczy podczas sesji retrospektywnych, jako że celem artykułu jest analiza kwestionariuszy badających postrzeganie ich roli przez studentów tłumaczenia symultanicznego.

Badanie ankietowe będące przedmiotem analizy w niniejszym artykule jest częścią badania eksperymentalnego mającego na celu zbadanie wpływu dwóch rodzajów bodźca (transkrypcji tekstu wyjściowego i nagrania tłumaczenia) na informacyjność werbalizacji, ich obfitość oraz dokładność. Celem badania było również zbadanie postrzegania roli bodźca przez osoby biorące udział w eksperymencie. Wyniki zostały omówione w artykule „Retrospective protocols in simultaneous interpreting: testing the effect of retrieval cues" (Gumul 2020a). W niniejszej pracy przybliżymy je w skrócie, aby nakreślić kontekst badania, w ramach którego przeprowadzono analizowane tu ankiety. Następnie w części analitycznej niniejszej pracy przedstawiona zostanie niepublikowana dotąd bardziej szczegółowa analiza odpowiedzi na pytania zawarte w kwestionariuszu.

\section{Rola bodźca podczas retrospekcji}

Wykorzystanie metody protokołów retrospektywnych do badania procesu tłumaczenia wymusza użycie dodatkowych bodźców stymulujących pamięć. Nawet jeśli spełniony jest warunek natychmiastowości, tj. sesja retrospektywna odbywa się zaraz po ukończeniu tłumaczenia, to długość tego typu zadań (na ogół od kilku do kilkunastu minut) sprawia, że tłumaczowi bardzo trudno odtworzyć z pamięci proces tłumaczenia. Oczywiście możliwa jest retrospekcja bez wykorzystania żadnego bodźca, jak np. w pracy Herring (2018). Jak wskazują Herring i Tiselius (2020), jest to rozwiązanie metodologicznie poprawne. Należy jednak liczyć się ze skąpymi i zniekształconymi raportami ze względu na ograniczenia pamięci. Właściwie tylko zadania 
o długości nieprzekraczającej kilku sekund dają gwarancję pełnego raportu retrospektywnego, jako że badany korzysta jeszcze z pamięci krótkotrwałej. Taka długość zadań jest możliwa w psychologii (Ericsson, Simon 1993). Jednak tłumacze podczas retrospekcji korzystają już z zasobów pamięci długotrwałej. Konsekwencją jest utrata danych pamięciowych i niepełny raport, jako że nie każdy ślad pamięciowy ulega konsolidacji i przechodzi do pamięci długotrwałej. $Z$ tego powodu większość badaczy stosujących tę metodę na potrzeby badań translatorycznych decyduje się na zastosowanie bodźca stymulującego pamięć.

Bodźce stosowane w dotychczasowych badaniach nad przekładem ustnym to:

- transkrypcja tekstu wyjściowego (np. Ivanova 2000; Englund Dimitrova, Tiselius 2009, 2014; Tiselius, Jenset 2011; Hild 2015),

- nagranie tekstu wyjściowego (np. Russell, Winston 2014; Shamy, de Pedro Ricoy 2017),

- nagranie tekstu docelowego, w przypadku tłumaczenia symultanicznego często z tekstem wyjściowym słyszanym w tle (np. Mead 2002; Napier 2004; Napier, Barker 2004; Bartłomiejczyk 2006; Gumul 2006, 2017, 2021),

- transkrypcja tekstu wyjściowego w połączeniu z nagraniem tekstu docelowego (np. Monacelli 2000; Vik-Tuovinen 2002; Chang, Schallert 2007; Tang 2018).

Dobór bodźca stymulującego pamięć tłumaczy zależy od wielu czynników. Jednym z nich jest rodzaj przekładu. Na przykład w tłumaczeniu symultanicznym tekst wyjściowy ma formę monologu i jako taki stanowi bardziej „statyczny” akt komunikacji. Dzięki temu łatwiej sporządzić transkrypcję oryginału, nawet w sytuacji, gdy mamy do czynienia $\mathrm{z}$ tekstem wygłoszonym spontanicznie. Natomiast w przypadku tłumaczenia dialogicznego akt komunikacji przebiega bardzo dynamicznie - kwestie wygłaszane przez rozmówców są zależne od reakcji ich interlokutora, a także strategii tłumaczenia i rozwiązań przyjętych przez tłumacza. Jak podkreślają Herring i Tiselius (2020), sporządzenie transkrypcji na potrzeby badania zaburza interakcję. Z kolei przygotowanie transkrypcji po tłumaczeniu jest na tyle czasochłonne, że znacznie opóźniłoby retrospekcję, uniemożliwiając w ten sposób spełnienie warunku natychmiastowości. $Z$ tego powodu na potrzeby tłumaczenia dialogicznego Herring (2018) proponuje trzyetapową procedurę retrospektywną. W pierwszym etapie nie przewidziano żadnego bodźca. 
Badaczka ograniczyła się do wydania instrukcji, aby tłumacze opowiedzieli, o czym myśleli podczas zadania. W drugiej fazie retrospekcji zastosowano już bodziec - tłumacze otrzymali arkusz z wyszczególnionymi głównymi punktami interakcji. Podobnie jak w pierwszej fazie ich zadaniem było odtworzenie procesu myślowego podczas tłumaczenia. W ostatniej fazie retrospekcja przybrała formę wywiadu, podczas którego tłumaczy zapytano m.in. o stopień trudności tłumaczenia, ich samopoczucie i emocje odczuwane podczas tłumaczenia, świadomość reakcji pozostałych uczestników interakcji oraz identyfikację $\mathrm{z}$ interlokutorami.

Czynnikiem determinującym dobór bodźca może być także cel badania. Przykładowo, jeśli analiza dotyczy stopnia zautomatyzowania strategii tłumaczeniowych bądź (nie)świadomego zastosowania pewnych form językowych, retrospekcja w formie wywiadu może zafałszować wyniki poprzez zwrócenie uwagi tłumaczy na wybory, których w rzeczywistości nie dokonali świadomie. Istnieje ryzyko, że uzyskane w ten sposób werbalizacje będą tak naprawdę reakcją na pytanie badacza i próbą spekulacji na temat przyjętych rozwiązań, a nie odzwierciedleniem toku myślenia w czasie zadania tłumaczeniowego. W tak ukierunkowanych badaniach wskazane jest zatem użycie transkrypcji/nagrania tekstu wyjściowego lub nagrania przekładu, by stymulować pamięć tłumaczy.

Przegląd wykonanych dotychczas badań z użyciem tej metody wskazuje, że wybór bodźca jest także uzależniony od preferencji badaczy i ich przekonania o przewadze jednego z nich. Niektórzy badacze, którzy decydują się na użycie tekstu wyjściowego (transkrypcji lub nagrania), negują stosowanie nagrania tekstu docelowego (Ivanova 2000; Englund Dimitrova, Tiselius 2009; Herring, Tiselius 2020) ze względu na ryzyko uzyskania werbalizacji, które są tak naprawdę wnioskami poczynionymi post factum, a nie odzwierciedleniem toku myślenia w czasie zadania tłumaczeniowego. Niewątpliwie konfrontacja z produktem tłumaczenia może sprawić, że werbalizacje tłumaczy mogą zawierać także komentarze na temat samego produktu końcowego, a nie tylko procesu przekładu, który jest celem retrospekcji.

Niestety również drugi z wyżej wymienionych bodźców (transkrypcja tekstu wyjściowego) niesie za sobą ryzyko zniekształcenia śladu pamięciowego. W badaniach zachowań konsumenckich z użyciem metody retrospekcji Büttner i Silberer (2008) zwracają uwagę na zjawisko zarządzania wrażeniem (impression management). Brak konfrontacji z produktem tłumaczenia może prowadzić do koloryzowania i przedstawiania procesu 
takim, jakim tłumacze chcieliby, by był widziany. Istnieje też ryzyko, że tłumacze będą opisywać nowe rozwiązania, które przychodzą im do głowy dopiero podczas retrospekcji, a nie tylko te zastosowane podczas zadania tłumaczeniowego. Problem ten wiąże się ściśle $\mathrm{z}$ ograniczeniami pamięci tłumaczy, które w większym stopniu dotyczą tekstu wyjściowego jako bodźca, gdyż ten słabiej stymuluje pamięć. Nowe pomysły mogą zatem „wypierać” zapamiętane decyzje.

Wydaje się zatem, że każdy z tych bodźców może powodować takie czy inne zniekształcenia, a debata tocząca się od dawna w środowisku translatologów na temat przewagi użycia tekstu wyjściowego lub docelowego jako bodźca nie jest oparta na badaniach empirycznych. Skłoniła ona więc autorkę niniejszego artykułu do przeprowadzenia wspominanego we wstępie badania empirycznego testującego wpływ rodzaju bodźca na informacyjność werbalizacji, ich obfitość oraz dokładność (Gumul 2020a). Badanie miało formę eksperymentu. Brały w nim udział dwie grupy uczestników. Pełna randomizacja, czyli losowy dobór uczestników badania, nie była możliwa ze względu na ograniczoną liczbę studentów tłumaczenia spełniających warunek odbycia minimum 60 godzin zajęć z tłumaczenia symultanicznego oraz wymóg wielkości próby umożliwiający inferencyjną analizę statystyczną. Badaniu zostali poddani zatem wszyscy studenci IV i V roku specjalności tłumaczeniowej filologii angielskiej Uniwersytetu Śląskiego, którzy wyrazili na to zgodę, a nie tylko ci losowo wybrani spośród całej populacji. Badanie można jednak uznać za eksperymentalne, ponieważ uczestnicy zostali przyporządkowani do poszczególnych grup za pomocą tablicy liczb losowych (Brzeziński 2008: 247).

Losowy przydział do grup eksperymentalnych był możliwy, ponieważ zmienną różnicującą dwie grupy był bodziec stymulujący pamięć tłumaczy podczas retrospekcji, czyli element zadania, a nie cechy badanych osób (np. tłumacze zawodowi versus studenci).Zastosowano porównanie międzygrupowe (between-group design): w grupie A bodźcem stymulującym pamięć tłumaczy była transkrypcja tekstu wyjściowego, a w grupie B nagranie tłumaczenia każdego z badanych. Rodzaj bodźca był zatem zmienną niezależną, natomiast parametry obfitości, informacyjności oraz dokładności werbalizacji retrospektywnych badanych tłumaczy stanowiły zmienne zależne.

Pierwsza ze zmiennych zależnych, tj. obfitość raportów werbalnych, została zoperacjonalizowana na potrzeby tego badania jako liczba komentarzy składających się na protokół retrospektywny danej osoby oraz liczba słów 
w całym protokole. Założono także, że stopień koncentracji czterech aspektów przetwarzania w tłumaczeniu symultanicznym w raportach badanych tłumaczy będzie odzwierciedlał informacyjność werbalizacji retrospektywnych. Wzięto pod uwagę następujące aspekty: problem z przetwarzaniem tekstu, źródło problemu, użytą strategię oraz powód użycia danej strategii. Werbalizacje, w których wspomniano wszystkie cztery czynniki, uznano za najbardziej informacyjne. Ostatnia zmienna zależna, tj. dokładność raportów, została zmierzona poprzez triangulację z produktem tłumaczenia. Zweryfikowano zbieżność pomiędzy raportami retrospektywnymi dotyczącymi użycia strategii a strategiami widocznymi w produkcie przekładu oraz zbieżność pomiędzy raportami opisującymi problemy z przetwarzaniem a trzema rodzajami zakłóceń płynności wypowiedzi: niewypełnionymi pauzami powyżej 2 sekund, przerwaniami fonetycznymi, zwanymi też wypełnionymi pauzami (np. yyy, eee), oraz zatrzymaniami startu (tj. powtarzaniem pierwszej głoski lub sylaby wyrazu następującego).

Uczestnikami badania było 36 studentów IV i V roku specjalności tłumaczeniowej filologii angielskiej Uniwersytetu Śląskiego. Wszyscy uczestnicy byli rodzimymi użytkownikami języka polskiego, a język angielski był dla każdego z nich językiem B. W eksperymencie wzięło udział 14 mężczyzn i 22 kobiety w wieku od 21 do 25 lat $(M=22,88 ; M d N=23 ; S D=1,06)$.

Jako tekst wyjściowy wybrano fragment (00:00 - 08:43) wystąpienia Pameli Meyer „How to spot a liar” (2011). Tekst cechuje znaczna gęstość informacyjna oraz bardzo szybkie tempo wypowiedzi - średnio około 170 słów na minutę. Występują w nim też liczne odniesienia kulturowe, wyliczenia, nazwy własne oraz liczby. Wybór tekstu o tak dużym stopniu trudności był świadomym działaniem badaczki, ponieważ jak podkreślają Englund Dimitrova i Tiselius (2009: 115), liczne problemy z przetwarzaniem tekstu przekładają się na bardziej obfite raporty werbalne podczas retrospekcji. Czynnik ten wydaje się szczególnie istotny w przypadku badania ukierunkowanego na zmierzenie obfitości i informacyjności werbalizacji. W takim wypadku lakoniczne raporty można w większym stopniu przypisać wpływowi bodźca stymulującego pamięć, a nie brakowi problemów z przetwarzaniem tekstu ${ }^{1}$.

1 Procedurę badawczą i wszystkie elementy składowe badania opisano szczegółowo w pracy Gumul (2020a). 
Wyniki sugerują, że wpływ rodzaju bodźca na analizowane w tym badaniu mierzalne parametry raportów retrospektywnych może być mniejszy, niż do tej pory uważano. Jeśli chodzi o parametr obfitości werbalizacji, nie wykazano statystycznie istotnej różnicy ani pod względem liczby komentarzy ( $\mathrm{w}$ teście analizy wariancji według rang Kruskal-Wallisa uzyskano wynik: $H=0,703, p=0,4)$, ani porównując liczbę słów $(H=0,38, p=0,53)$, mimo że w grupie B zaobserwowano dłuższe komentarze średnio o $20 \%$ w porównaniu $z$ grupą A (Gumul 2020a: 159-160).

Brak istotnych różnic wykazała również analiza parametru informacyjności raportów. Jeśli chodzi o wzmianki o problemach z przetwarzaniem oraz wskazanie źródeł problemów, wyniki są porównywalne. Natomiast zaobserwowano przewagę werbalizacji dotyczących strategii oraz powodów ich zastosowania $\mathrm{w}$ raportach grupy $\mathrm{B}$. Jednak również te różnice okazały się statystycznie nieistotne. W przypadku wzmianek na temat strategii w teście ANOVA uzyskano wynik: $F=2,636, p=0,11$, a dla kategorii podania powodu użycia strategii: $F=1,633, p=0,2$. Największe dysproporcje zaobserwowano $\mathrm{w}$ drugim etapie analizy informacyjności raportów. Pod względem stopnia koncentracji wyżej wspomnianych czterech czynników komentarze retrospektywne, w których badani tłumacze wymieniają 3 i 4 czynniki, przeważają w grupie B, podczas gdy do pozostałych trzech kategorii ( 0,1 i 2 czynniki) zaklasyfikowano więcej komentarzy z grupy A. Sugeruje to, że użycie nagrania tekstu docelowego jako bodźca skutkuje większą informacyjnością raportów. Nie potwierdziła tego jednak analiza statystyczna. Dla żadnej z tych kategorii nie uzyskano statystycznie istotnej różnicy w teście Kruskal-Wallisa (dla kategorii 4 czynników: $H=0,529, p=$ 0,46; dla 3: $H=2,865, p=0,09$; dla 2: $H=0,676, p=0,41$; dla $1: H=1,123$, $p=0,28$; dla 0: $H=0,993, p=0,31$ ) (Gumul 2020a: 162-163).

Jeśli chodzi o ostatni z trzech analizowanych parametrów, tj. dokładność werbalizacji retrospektywnych, można założyć, że w przypadku gdy bodźcem jest produkt przekładu, czyli nagranie tekstu docelowego, raporty tłumaczy będą bardziej precyzyjne. Pytania badawcze sformułowano zatem inaczej niż w przypadku pozostałych parametrów. Celem analizy było zbadanie, czy dokładność werbalizacji retrospektywnych będzie znacząco większa w grupie B, w której bodźcem stymulującym pamięć było nagranie tłumaczenia. Porównanie raportowania strategii i powodów ich użycia wykazało nieznacznie większą dokładność raportów w grupie B. Różnica ta okazała się nieistotna statystycznie $(H=0,757, p=0,38)$. Również drugi etap analizy 
dokładności raportów retrospektywnych - porównanie werbalizacji raportujących problemy w przetwarzaniu z zakłóceniami płynności wypowiedzi - nie wykazał statystycznie istotnej różnicy $(H=2,306, p=0,12)$ mimo nieznacznej procentowej przewagi w grupie B (Gumul 2020a: 164-165).

\section{Ocena roli bodźca podczas retrospekcji - wyniki ankiet}

Celem opisanego powyżej badania była także określenie postrzegania roli bodźca przez studentów tłumaczenia biorących udział w tym eksperymencie. Tę część badania przeprowadzono za pomocą kwestionariusza ankietowego.

Przygotowany przez autorkę kwestionariusz miał dwie wersje: wersja A dla grupy eksperymentalnej, w której bodźcem stymulującym pamięć podczas retrospekcji była transkrypcja tekstu wyjściowego (zob. Załącznik 1), oraz wersja B dla grupy, w której bodźcem było nagranie tekstu docelowego (zob. Załącznik 2). Uczestnicy badania zostali poproszeni o wypełnienie kwestionariusza zaraz po zakończeniu retrospekcji. Analiza odpowiedzi na siedem pytań składających się na tę ankietę zostanie przedstawiona w kolejnych podrozdziałach.

\subsection{Ocena stopnia trudności przypominania}

W pytaniu 1 respondenci zostali poproszeni o subiektywną ocenę stopnia trudności przypominania podczas retrospekcji decyzji podjętych w trakcie tłumaczenia. Badani mieli do wyboru pięć opcji: od „bardzo łatwo” do "bardzo trudno” (zob. Załączniki 1 i 2). Pytanie zawierało też miejsce na dodatkowy komentarz.W grupie A, w której bodźcem była transkrypcja tekstu wyjściowego, sześć na szesnaście osób określiło, że podczas retrospekcji trudno było przypomnieć im sobie decyzje podjęte w trakcie tłumaczenia, a kolejne cztery wybrały opcję „bardzo trudno”. Dwóch tłumaczy uznało, że dość łatwo było im odtworzyć tok myślenia, a tylko jedna osoba wybrała odpowiedź „łatwo”. Wyniki te różnią się od odpowiedzi uzyskanych w grupie B, w której bodźcem stymulującym pamięć było nagranie własnego tłumaczenia: tylko jedna osoba zaznaczyła największy stopień trudności, a cztery kolejne wybrały odpowiedź „trudno”. Trzech respondentów określiło, że 
bardzo łatwo było im sobie przypomnieć decyzje podjęte w trakcie tłumaczenia, a aż siedmiu wybrało opcję „dość łatwo”. Wyniki te wydają się oczywiste, biorąc pod uwagę, że respondenci w grupie B mieli bezpośredni dostęp do własnych tłumaczeń i podczas retrospekcji mogli śledzić zastosowane przez siebie rozwiązania. Jednak komentarze tłumaczy do tego pytania oraz odpowiedzi na pytanie 2 , w którym osoby, które zaznaczyły w pytaniu 1 opcje „trudno" i „bardzo trudno”, zostały poproszone o sprecyzowanie, co utrudniło przypomnienie decyzji, wskazują na szereg innych czynników. Jedynie dwóch respondentów w grupie A, która miała do dyspozycji transkrypcję tekstu oryginalnego, wspomniało o braku możliwości odsłuchania własnego tłumaczenia. Natomiast cztery osoby z tej grupy jako czynnik utrudniający przypomnienie podało ograniczenia tłumaczenia symultanicznego. Ilustrują to poniższe komentarze:

(1)

A/Pyt. 1: Tłumaczenie symultaniczne jest dla mnie bardzo stresujące. Zdecydowanie sobie nie radzę, więc po zakończeniu decyzje podjęte podczas tłumaczenia czy nawet content tekstu wylatuje mi z pamięci.

A/Pyt. 2: Myślę, że przez ilość informacji, które docierają do tłumacza symultanicznego w tak krótkim czasie, bardzo trudno jest wyłapać i zapamiętać wszystkie decyzje podjęte w trakcie tłumaczenia.

A/Pyt. 2: Wydaje mi się, że w sytuacji stresującej, jaką jest tłumaczenie symultaniczne, mój mózg się „wyłącza” i ciężko jest mi przypomnieć sobie, jakie decyzje podejmowałam.

Przywołane przez tłumaczy problemy z zapamiętaniem decyzji podjętych podczas tłumaczenia wynikają ze specyfiki przekładu symultanicznego i złożoności składających się na niego procesów kognitywnych. Jak podkreśla Gile (2009), w porównaniu z tłumaczami pisemnymi, tłumacze symultaniczni $\mathrm{w}$ mniejszym stopniu zachowują $\mathrm{w}$ pamięci tłumaczony tekst $\mathrm{z}$ powodu znacznie większego obciążenia kognitywnego. Podobnie jest w przypadku podejmowanych podczas tłumaczenia decyzji.

Na niemożność odtworzenia z pamięci pełnego toku myślenia wynikającą ze specyfiki tłumaczenia symultanicznego zwróciła również uwagę kolejna osoba z grupy A. U tłumaczy ustnych, zwłaszcza tych doświadczonych, 
użycie wielu technik i strategii jest w znacznym stopniu zautomatyzowane (Kohn, Kalina 1996; Liontou 2011). Takie nieświadome, odruchowe procesy, podobnie jak czynności powtarzalne, nie pozostawiają śladu w pamięci i nie można ich potem odtworzyć podczas retrospekcji. Niekompletność raportów retrospektywnych wynika zatem nie tylko z ograniczeń pamięci, ale również $\mathrm{z}$ automatyzacji pewnych procesów tłumaczeniowych.

(4)

A/Pyt. 1: Część z podjętych przeze mnie decyzji takich jak uogólnienia i pominięcia nie stanowiły większego problemu, jeśli chodzi o przypomnienie sobie ich zastosowania. Jednakże na pewno część technik została użyta nieświadomie i nie byłam w stanie sobie ich przypomnieć.

Ten sam powód trudności z przypomnieniem sobie decyzji tłumaczeniowych podczas retrospekcji podało aż pięciu respondentów z grupy B. Przypuszczalnie konfrontacja z produktem przekładu uświadomiła im, że nie są $\mathrm{w}$ stanie podać powodów zastosowania pewnych strategii widocznych w tekście docelowym, co ilustruje poniższy komentarz:

(5)

B/Pyt. 2: Prawdę mówiąc, tłumacząc, nie zastanawiam się, jakich strategii tłumaczeniowych używam. Robię to instynktownie. Nie mogłam też porównać mojego tłumaczenia z oryginałem. Ponieważ nie pamiętam dokładnie oryginalnego tekstu, nie wiem, które fragmenty były problematyczne, i nie wiem, czy coś pominęłam, wybrnęłam z problemu opisowo czy nieświadomie zastosowałam inną technikę. Tekst był dla mnie na tyle trudny, że niestety były momenty ciszy, bo wypadałam na moment z rytmu lub nie rozumiałam mówcy.

W komentarzu tym tłumaczka podkreśla brak dostępu do tekstu wyjściowego. O ile, jak już wcześniej wspomniano, w grupie A jedynie dwóch respondentów skarżyło się na brak dostępu do nagrania własnego tłumaczenia, o tyle w grupie B aż siedmiu tłumaczy odczuwało brak transkrypcji tekstu wyjściowego podczas retrospekcji. Wydaje się zatem, że w odczuciu badanych bardziej pożądana jest transkrypcja oryginału jako bodziec stymulujący pamięć. Pokazują to komentarze do pytania 1 oraz odpowiedzi na pytanie 2 kolejnych respondentów. 
(6)

B/Pyt. 1: Myślę, że jeśli miałabym przed oczami transkrypt, byłoby mi nieco łatwiej przypomnieć sobie konkretne decyzje, na przykład pominięcia itp.

(7)

B/Pyt. 2: Brak oryginalnego tekstu sprawił, że ciężko było przypomnieć sobie, dlaczego podejmowałem różne decyzje dotyczące tłumaczenia.

(8)

B/Pyt. 1: Nie pamiętałem oryginalnego tekstu, więc trudno było mi przypomnieć sobie, dlaczego podejmowałem takie, a nie inne decyzje.

Trzy osoby w grupie B upatrywały problemy z przypominaniem sobie swoich decyzji tłumaczeniowych w szybkim tempie wygłaszania tekstu wyjściowego i jego gęstości informacyjnej. Oba te czynniki w odczuciu tłumaczy stanowiły na tyle duże obciążenie kognitywne, że trudno im było świadomie podejmować decyzje i zapamiętać te, które podjęli.

(9)

B/Pyt. 1: Zbyt szybki tekst nie dawał możliwości na podjęcie decyzji o strategii ani na przeanalizowanie tekstu. Nie wiem, o czym myślałam.

B/Pyt. 2: Tempo tekstu i nagromadzenie przekazywanych informacji.

Osoby, dla których przypomnienie sobie decyzji tłumaczeniowych na potrzeby retrospekcji nie stanowiło problemu (tzn. te, które wybrały odpowiedź „łatwo” lub „dość łatwo” - dziesięć osób w grupie B i dwie osoby w grupie A), podawały jako powody długość zadania tłumaczeniowego i przeprowadzenie retrospekcji bezpośrednio po tłumaczeniu. Ilustrują to dwa komentarze tłumaczy z grupy $\mathrm{B}$.

(10)

B/Pyt. 1: Uważam, że gdyby tekst do tłumaczenia był dłuższy niż 10 minut, mogłyby wystąpić związane z zapamiętywaniem problemy. Jednak nie wystąpiły one w tekście o długości poniżej 10 minut.

B/Pyt. 1: Tekst był odtwarzany krótko po nagrywaniu, dzięki czemu nadal pamiętałam fragmenty i problemy. 
Oba wymienione przez respondentów czynniki są związane $\mathrm{z}$ natychmiastowością retrospekcji. Ten aspekt jest uważany za jeden $\mathrm{z}$ najistotniejszych czynników w projektowaniu badań opartych na retrospekcji, ponieważ ogranicza utratę danych pamięciowych. Według Ericssona i Simona (1993), stosujących tę metodę w badaniach psychologicznych, pełne odtworzenie toku myślenia podczas zadania jest możliwe jedynie wtedy, gdy retrospekcja jest przeprowadzana natychmiast po ukończeniu tego zadania i gdy zadanie to trwa nie dłużej niż 10 sekund. O ile pierwszy postulat jest najczęściej przestrzegany w badaniach nad przekładem, zwłaszcza tych przeprowadzonych $\mathrm{w}$ warunkach laboratoryjnych na potrzeby eksperymentów lub symulacji pracy tłumaczy, o tyle spełnienie postawionego przez Ericssona i Simona (1993) warunku długości zadania jest właściwie nierealne w badaniach translatorycznych (zob. Gumul 2019: 177-178). Najczęściej zadanie jest skracane do kilku minut (np. Englund Dimitrova, Tiselius 2014), co należałoby uznać za kompromis pomiędzy narzuconym przez metodę warunkiem długości zadania a realiami pracy tłumaczy konferencyjnych.

\subsection{Czynniki ułatwiające retrospekcję}

Kolejne dwa pytania (pytania 3 i 4), wspólne dla obu wersji kwestionariusza, dotyczyły czynników ułatwiających przypominanie podczas retrospekcji. W pytaniu 3 zapytano respondentów, co ułatwiło przypomnienie sobie decyzji podjętych w trakcie tłumaczenia, natomiast w pytaniu 4 poproszono badanych o wymienienie dodatkowych czynników, które mogłyby ułatwić retrospekcję.

Jeśli chodzi o pytanie 3, widać wyraźną różnicę pomiędzy grupą A (używającą transkrypcji jako bodźca stymulującego pamięć) i grupą B (używającą nagrania własnego tłumaczenia w tym samym celu). Aż dziesięciu respondentów w grupie A wymieniło transkrypcję jako czynnik ułatwiający retrospekcję, podczas gdy tylko czterech tłumaczy z grupy B uznało dostęp do nagrania za czynnik efektywnie stymulujący pamięć w czasie retrospekcji (przykład 11). Jest to spójne z odpowiedziami na pytania 1 i 2, w których badani w grupie B wymieniali brak dostępu do transkrypcji jako czynnik utrudniający przypominanie. 
(12)

A/Pyt. 3: Dostęp do skryptu tekstu wyjściowego pobudzał pamięć. Również fakt, że omawialiśmy je [swoje decyzje] zaraz po zakończeniu tłumaczenia.

Wyżej wymieniona natychmiastowość retrospekcji została przywołana przez czterech respondentów w grupie B i dwóch w grupie A. Inny czynnik wspólny dla obu grup to problemy podczas tłumaczenia. Jak wynika z wypowiedzi badanych, trudności, jakich doświadczyli podczas tłumaczenia, sprawiają, że lepiej pamiętają decyzje podjęte w tych fragmentach tekstu. O tym czynniku stymulującym pamięć wspomniało pięciu respondentów z grupy B i dwóch z grupy A (przykłady 12-14). Na ten aspekt stymulacji pamięci podczas retrospekcji zwróciły także uwagę w swojej pracy na temat wykorzystania tej metody w badaniach nad przekładem Englund Dimitrova i Tiselius (2009: 115). Badaczki utrzymują, że problemy z przetwarzaniem tekstu podczas tłumaczenia skutkują obszerniejszymi i bogatszymi raportami retrospektywnymi.

B/Pyt. 3: Zazwyczaj pamiętam fragmenty, które sprawiają mi jakiś problem, i wiem, z czego wynikała taka, a nie inna decyzja podczas tłumaczenia.

B/Pyt. 3: Podczas trudniejszych fragmentów przemówienia musiałem podjąć szybko decyzje, co zrobić, i te decyzje bardziej zapadły mi w pamięć.

A/Pyt. 3: Dobrze pamiętałam użycie technik użytych we fragmentach, które w trakcie tłumaczenia były dla mnie problematyczne, np. konieczność zastosowania uogólnień z powodu dużej ilości szczegółów.

Innym czynnikiem ułatwiającym przypomnienie sobie decyzji podjętych $\mathrm{w}$ trakcie tłumaczenia są według relacji tłumaczy cechy charakterystyczne tekstu wyjściowego, takie jak humor, odniesienia kulturowe oraz liczby (przykład 15). Na ten aspekt zwrócili uwagę jedynie respondenci z grupy A (trzy osoby) mający do dyspozycji transkrypcję tekstu wyjściowego. Widać więc wyraźny wpływ bodźca na proces retrospekcji, podobnie jak w przypadku dominującej w grupie B odpowiedzi przypisującej lepszą stymulację pamięci problemom doświadczonym podczas tłumaczenia. 
A/Pyt. 3: Były to charakterystyczne lub nieznane mi nazwiska, liczby oraz instytucje. Również widząc w tekście wymieniane przez mówczynię elementy, byłam w stanie powiedzieć, które zostały przeze mnie pominięte. W wypowiedzi było wiele charakterystycznych elementów, dzięki którym przypomniałam sobie, co powiedziałam w tłumaczeniu, takie jak goryl Koko czy Starbucks.

W odpowiedzi na kolejne pytanie (o czynniki, które potencjalnie mogłyby ułatwić przypomnienie sobie decyzji podjętych w trakcie tłumaczenia) czterech respondentów z grupy A zadeklarowało, że wolałoby wysłuchać nagrania zamiast czytać transkrypcję. Porównywalna liczba respondentów $\mathrm{w}$ grupie $\mathrm{B}$ (dwie osoby) również wymieniła bodziec, do którego nie miała dostępu, czyli transkrypcję. Natomiast trzy kolejne osoby w grupie A uznały, że najlepszym rozwiązaniem byłoby wysłuchanie nagrania połączone $\mathrm{z}$ wglądem do transkrypcji. Ten sam czynnik wymieniło dwóch respondentów w grupie B (przykład 17).

B/Pyt. 4: Ponowne odsłuchanie tekstu oryginalnego lub transkrypt tekstu. Wiedziałbym wtedy dokładnie, co, kiedy i dlaczego pominąłem. Najlepszym rozwiązaniem byłoby odsłuchiwanie swojego tłumaczenia wraz z dostępnym transkryptem oryginalnego nagrania.

Inne czynniki, które mogłyby w odczuciu badanych pomóc im w retrospekcji, to dla grupy A: lepsza koncentracja podczas tłumaczenia (dwie osoby) oraz dostęp do transkrypcji własnego tłumaczenia (jedna osoba). Jedna z osób z tej grupy uznała, że przypomnienie sobie decyzji podjętych w czasie tłumaczenia byłoby łatwiejsze, gdyby została poinformowana przed zadaniem, czego będzie dotyczyć retrospekcja (przykład 18).W grupie B dwie osoby wymieniły ten czynnik. Procedura badawcza celowo zakładała nieujawnianie badanym tłumaczom celu retrospekcji przed zadaniem przekładowym, po to aby nie wpływać na ich tłumaczenie i nie zafałszować wyników badania.

A/Pyt. 4: Gdyby przed rozpoczęciem nagrania powiedziano nam, by zwrócić uwagę na podjęte decyzje, to możliwe, że zapamiętalibyśmy ich więcej. 
Z kolei respondenci z grupy B wymienili także następujące czynniki, które mogłyby ułatwić retrospekcję: wolniejsze tempo wygłaszania tekstu wyjściowego (dwie osoby) i możliwość ponownego wysłuchania nagrania własnego tłumaczenia (dwie osoby).

\subsection{Ocena roli bodźca}

Pytania 5 i 6 różniły się w zależności od grupy eksperymentalnej. Grupa A, dla której bodźcem była transkrypcja tekstu wyjściowego, została zapytana, na ile pomocny okazał się ten bodziec stymulujący pamięć (pytanie 5). Respondenci zostali poproszeni o ocenę efektywności bodźca w skali od 1 (bardzo pomocny) do 5 (całkowicie bezużyteczny) oraz o uzasadnienie swojego wyboru w części opisowej pytania (Załączniki 1 i 2). Z kolei w pytaniu 6 zostali poproszeni o ocenę, na ile bodziec, do którego nie mieli dostępu (tj. nagranie własnego tłumaczenia), mógłby okazać się pomocny. Podobnie jak pytanie 5, to pytanie również zawierało prośbę o uzasadnienie oceny. W przypadku grupy B pytania te były odwrócone: pytanie 5 dotyczyło nagrania tłumaczenia badanych tłumaczy, a pytanie 6 transkrypcji.

Większość respondentów w obu grupach oceniła bodziec, który miała do dyspozycji, jako bardzo pomocny lub pomocny (szesnaście osób w grupie A i czternaście osób w grupie B). Po dwie osoby z każdej grupy określiły go jako dość pomocny. Jedynie dwie osoby w grupie B uznały, że przedstawione im nagranie własnego tłumaczenia nie miało dla nich znaczenia, jeśli chodzi o stymulację pamięci podczas retrospekcji. W uzasadnieniu swojej oceny roli bodźca respondenci z grupy A, którzy ocenili możliwość wglądu w transkrypcję jako pomocną lub bardzo pomocną, wymienili takie czynniki jak: cechy tekstu wyjściowego (przykład 19) oraz ograniczenia wynikające z długości tekstu (przykład 20).

A/Pyt. 5: Czytając tekst wyjściowy, byłam w stanie wrócić myślami do tłumaczenia, które wykonałam. Dzięki charakterystycznym momentom wypowiedzi mogłam odtworzyć tłumaczenie. Mimo że wypowiedź była spójna, nie byłam w stanie przypomnieć sobie większości wypowiedzi bez tekstu. 
(20)

A/Pyt. 5: Po zakończeniu tłumaczenia ciężko byłoby przypomnieć sobie bez transkrypcji całe 9 minut przemowy.

W swojej odpowiedzi na to pytanie jedna $\mathrm{z}$ badanych osób zwróciła uwagę na interesujący aspekt użycia bodźca stymulującego pamięć podczas retrospekcji. Wypowiedź ta sugeruje, że dobór efektywnego bodźca zależy przynajmniej w pewnym stopniu od preferencji sensorycznych w przyswajaniu i przetwarzaniu informacji: dominacji wzrokowej lub słuchowej.

A/Pyt. 5: Znacznie lepiej czuję się w tłumaczeniu pisemnym i dlatego czuję się bardziej komfortowo, widząc przed sobą tekst niż słuchając nagrania.

Z kolei respondenci z grupy B w odpowiedzi na to samo pytanie podkreślali przede wszystkim, że bez nagrania trudno byłoby odtworzyć z pamięci wszystkie podjęte decyzje (sześć osób). Jedna osoba zwróciła ponownie uwagę na ograniczenia przekładu ustnego, które w jej odczuciu utrudniają przypomnienie sobie podjętych decyzji.

B/Pyt. 5: Doświadczenie było tak intensywne, że mój mózg nie zapamiętał, czym się kierował ani dlaczego wykonywał pewne „ruchy”. Bez nagrania nie byłabym w stanie przypomnieć sobie zbyt wiele.

Jeden z respondentów, który zadeklarował, że wykorzystanie nagrania jako bodźca podczas retrospekcji nie miało dla niego znaczenia, uzasadnił łatwość zapamiętania podjętych decyzji niewielką długością tekstu:

B/Pyt. 5: Decyzje podjęte w przeciągu ośmiu minut trwania nagrania na tyle utkwiły mi w pamięci, iż niemożliwym byłoby zapomnieć o nich w przeciągu tych kilkunastu minut.

Odpowiedzi na pytanie 6, w którym zapytano respondentów, na ile pomocny byłby bodziec, do którego nie mieli dostępu podczas retrospekcji, różniły się w zależności od grupy badawczej. Większość studentów tłumacze- 
nia z grupy A uznała, że nagranie ich własnego tłumaczenia byłoby bardzo pomocne (osiem osób), pomocne (sześć osób) lub dość pomocne (trzy osoby). Tylko dla jednej osoby nagranie nie miałoby znaczenia. Natomiast zdania respondentów $\mathrm{z}$ grupy $\mathrm{B}$ na temat przydatności transkrypcji jako potencjalnego bodźca były bardziej podzielone. Aż cztery osoby uznały możliwość przeczytania transkrypcji tekstu wyjściowego za bezużyteczną, a trzy kolejne odpowiedziały, że nie miałoby to dla nich znaczenia. Jedynie trzy osoby uznały, że ten rodzaj bodźca mógłby być bardzo pomocny, dwie określiły go jako pomocny, a sześć jako dość pomocny.

Respondenci z grupy A uzasadniali swoją wysoką ocenę roli potencjalnego bodźca (nagrania tekstu docelowego w przypadku tej grupy eksperymentalnej) przede wszystkim efektywną, według nich, stymulacją pamięci. Pomimo tego, że nagranie pozwala na prześledzenie własnych wyborów, jedna $\mathrm{z}$ respondentek uznała transkrypcję za efektywniejszy bodziec właśnie ze względu na łatwość odtworzenia z pamięci zastosowanych technik, w jej odczuciu w większym stopniu niż w przypadku dostępu do nagrania.

A/Pyt. 6: Wydaje mi się, że wysłuchanie własnego nagrania byłoby pomocne, lecz nie w takim stopniu jak dostęp do transkryptu. Transkrypt pokazał mi fragmenty, które były dla mnie problematyczne i w których świadomie stosowałam techniki tłumaczeniowe. Przy nagraniu - finalnym produkcie - mogłabym nie rozpoznać części tekstu i nie przypomnieć sobie zastosowanej przeze mnie techniki.

$\mathrm{Z}$ kolei respondenci z grupy B, którzy pozytywnie ocenili rolę potencjalnego bodźca (tj. transkrypcji oryginalnego wystąpienia dla tej grupy), podkreślali, że tekst wyjściowy ułatwiłby przypomnienie sobie powodów pominięcia fragmentów. Niektórzy studenci z tej grupy, zarówno ci, którzy uznali potencjalny bodziec za pomocny, jak i ci, dla których rodzaj bodźca nie miał znaczenia, deklarowali, że najlepszym rozwiązaniem byłoby połączenie obu bodźców podczas retrospekcji (pięć osób).

B/Pyt. 6: Ponieważ w obu przypadkach miałabym tylko jedną wersję (oryginał lub moje tłumaczenie). Najprościej byłoby, gdybym odsłuchiwała swoje tłumaczenie, patrząc na transkrypcję oryginału. 
W odpowiedzi na to pytanie po raz kolejny pojawił się argument dotyczący preferencji sensorycznych. Jedna $\mathrm{z}$ respondentek $\mathrm{z}$ grupy $\mathrm{B}$ zadeklarowała dominację wizualną i z tego powodu uznała, że odpowiedniejszym bodźcem dla niej byłaby transkrypcja tekstu wyjściowego.

\section{(26)}

B/Pyt. 6: Jestem wzrokowcem, więc tekst pisemny zdecydowanie by mi pomógł odtworzyć pewne decyzje.

Ci respondenci, którzy uznali transkrypcję tekstu wyjściowego za bezużyteczną, przede wszystkim uzasadniali swoją ocenę ograniczeniami pojemności pamięci. Według nich nagranie własnego przekładu lepiej stymuluje pamięć.

\subsection{Ocena stopnia zniekształcenia danych pamięciowych przez bodziec}

W ostatnim pytaniu (7) zapytano respondentów, do jakiego stopnia wykorzystany podczas retrospekcji bodziec zniekształca zapamiętane decyzje. Zadaniem studentów była ocena stopnia zniekształcenia w czterostopniowej skali od 1 (w ogóle nie zniekształca) do 4 (bardzo zniekształca). Poproszono również badane osoby o uzasadnienie swojego wyboru. W każdej z badanych grup pytanie 7 dotyczyło tylko bodźca, do którego respondenci z danej grupy mieli dostęp. W grupie A zapytano zatem o transkrypcję tekstu wyjściowego, natomiast w grupie B o nagranie tekstu docelowego.

W literaturze przedmiotu pojawiają się opinie, że nagranie tekstu docelowego może zniekształcić wspomnienia w większym stopniu niż transkrypcja czy nagranie tekstu wyjściowego (zob. np. Englund Dimitrova, Tiselius 2009, 2014; Herring, Tiselius 2020). Dostęp do produktu tłumaczenia może sprawić, że tłumacze będą opisywać to, co dostrzegają podczas retrospekcji, zamiast tego, co pamiętają z procesu tłumaczenia. Na tej podstawie przyjęto hipotezę, że nagranie tłumaczenia będzie postrzegane przez badanych jako bodziec, który zniekształca zapamiętane decyzje w większym stopniu niż transkrypcja oryginału. Jednak wyniki nie potwierdzają tej hipotezy. Dziesięciu respondentów z grupy A i ośmiu z grupy B wybrało odpowiedź „w ogóle nie zniekształca, nie ma wpływu na zapamiętane decyzje”. Cztery osoby z grupy A i sześć z grupy B uznało, że bodziec, z którego korzystały podczas retrospekcji, 
zniekształca zapamiętane decyzje w niewielkim stopniu. Zaledwie sześciu respondentów uznało, że bodziec zniekształca ich wspomnienia procesu tłumaczenia (cztery osoby w grupie A i dwie osoby w grupie B). Tylko dwie osoby z grupy B wybrały odpowiedź „,bardzo zniekształca”. Uzyskane wyniki można zatem uznać za porównywalne dla obu grup. W odczuciu badanych studentów nie mamy do czynienia $\mathrm{z}$ wyraźną przewagą żadnego $\mathrm{z}$ bodźców, jeśli chodzi o ich wpływ na zniekształcenie zapamiętanych decyzji. Oczywiście, porównując wyniki obu grup, należy wziąć pod uwagę, że respondenci nie mieli możliwości porównania obu bodźców, a uzyskane odpowiedzi odzwierciedlają przede wszystkim ich subiektywne odczucia. Jednak wyniki te sugerują, że wpływ bodźca na zniekształcenie zapamiętanych procesów może być w rzeczywistości mniejszy, niż do tej pory zakładano. Dodatkowym dowodem na istnienie mniejszych różnic w tym względzie pomiędzy użyciem transkrypcji tekstu wyjściowego a nagraniem tekstu docelowego jako bodźca podczas retrospekcji są wypowiedzi badanych osób z grupy A (przykład 27), z których wynika, że to transkrypcja oryginału ma według nich wpływ na zniekształcenie zapamiętanych procesów.

\section{(27)}

A/Pyt. 7: Czytanie transkrypcji i spokojne jej przeanalizowanie sprawiło, że zaczęłam myśleć o lepszych rozwiązaniach i lepszych strategiach. Ciężko to nazwać, ale nowe pomysły wypierały z głowy to, co naprawdę się zdarzyło, kiedy tłumaczyłam ten tekst.

Warto podkreślić, że aż trzy osoby w grupie A wskazały na ryzyko zniekształcenia wspomnień przez bodziec, który uważany jest za mniej obarczony takim ryzykiem. W grupie B również pojawiły się wypowiedzi dotyczące zniekształcenia danych pamięciowych. Jednak w przypadku tego rodzaju bodźca, biorąc pod uwagę wyjściową hipotezę, można spodziewać się werbalizacji tłumaczy na ten temat. Wśród czynników zniekształcających wspomnienia badani wymieniali brzmienie własnego głosu (przykład 28) oraz konfrontację z popełnionymi przez siebie błędami (przykład 29). Jedna $\mathrm{z}$ respondentek zwróciła również uwagę na brak presji czasowej podczas retrospekcji w przeciwieństwie do samego zadania tłumaczenia symultanicznego, co w jej odczuciu może doprowadzić do wyjaśniania decyzji, które nie zostały podjęte świadomie podczas tłumaczenia (przykład 30). Jednak o ile pierwszy z wyżej wymienionych czynników został oceniony 
jako zniekształcający wspomnienia w największym stopniu (na $4 \mathrm{w}$ skali od 1 do 4), o tyle w pozostałych przypadkach respondenci wybrali opcję „zniekształca w niewielkim stopniu”.

B/Pyt. 7: Bardziej niż na tłumaczeniu skupiam się na tym, jak okropnie brzmi mój głos na nagraniu, co uniemożliwia mi przypomnienie sobie szczegółów odnośnie decyzji podjętych w procesie translacyjnym.

B/Pyt. 7: Odsłuchując własne nagranie, mimowolnie skupiam się bardziej na swoich błędach niż na przypomnieniu sobie decyzji podjętych w czasie tłumaczenia.

(30)

B/Pyt. 7: Tak, uważam, że wysłuchanie nagrania sprawia, że zniekształcone jest nieco nasze postrzeganie podjętych decyzji. Przez to, że mamy więcej czasu na porównanie i dokładne usłyszenie tego, co pominęliśmy, możemy opisać decyzje, nad którymi tak naprawdę nie myśleliśmy podczas tłumaczenia.

Jedna $\mathrm{z}$ respondentek, która uznała, że użyty w retrospekcji bodziec zniekształca zapamiętane decyzje jedynie w niewielkim stopniu, zwróciła uwagę na rolę odpowiednich instrukcji podanych badanym (przykład 31). Potwierdza to opinie badaczy, którzy twierdzą, że poproszenie tłumaczy, by ograniczyli się jedynie do werbalizowania decyzji świadomie podjętych podczas tłumaczenia, pozwala przynajmniej częściowo zniwelować negatywny wpływ bodźca i uzyskać dzięki metodzie retrospekcji werbalizacje, które odzwierciedlają procesy zachodzące podczas tłumaczenia (zob. np. Herring, Tiselius 2020; Gumul 2020a, 2020b).

B/Pyt. 7: Ponieważ w badaniu zapytano o zapamiętane decyzje, a nie wnioski wyciągnięte później, starałam się trzymać polecenia. Dlatego choć częściowo mogły zostać zniekształcone, nie było to znaczące.

Kolejnych dwóch respondentów podkreśliło, że w ich odczuciu to ograniczenia pamięci mogą mieć większy wpływ na uzyskane werbalizacje niż zniekształcenie wywołane przez użyty podczas retrospekcji bodziec. 
A/Pyt. 7: Nie zniekształca, ponieważ nie wydaje mi się, że powiedziałem coś innego podczas retrospekcji niż przy tłumaczeniu. Nie udało mi się przywołać wszystkich wspomnień, ale te przywołane nie uległy zmianie.

A/Pyt. 7: Jest to na pewno zależne od pamięci danego tłumacza.

Większość respondentów w tym badaniu pozytywnie oceniła rolę bodźca. Bez względu na rodzaj bodźca badani podkreślili przede wszystkim, że stymuluje on pamięć, czego przykładem są poniższe werbalizacje.

A/Pyt. 7: Zupełnie nie zniekształca. Wręcz przeciwnie, dzięki transkrypcji łatwiej wydobyłem z pamięci decyzje, które podjąłem w trakcie tłumaczenia.

A/Pyt. 7: Moim zdaniem nie zniekształca i nie ma wpływu na zapamiętane decyzje, ponieważ były one świadome.

\section{Podsumowanie}

Wyniki uzyskane w badaniu ankietowym nie potwierdzają opinii na temat obu bodźców, które pojawiają się w literaturze przedmiotu. Przykładem jest postrzeganie przez respondentów nagrania tłumaczenia jak bodźca stymulującego pamięć. Ten rodzaj bodźca uważa się za ułatwiający retrospekcję, ponieważ tłumacze mają dostęp do produktu tłumaczenia, dzięki czemu łatwiej im odtworzyć proces tłumaczenia. Nie potwierdzają tego jednak odpowiedzi respondentów w tym badaniu. Tylko nieliczni tłumacze, którzy mieli do dyspozycji transkrypcję tekstu wyjściowego, wskazali na brak dostępu do nagrania własnego tłumaczenia jako czynnik utrudniający przypominanie, podczas gdy niemal połowa badanych z drugiej grupy skarżyła się na brak możliwości śledzenia transkrypcji oryginału podczas retrospekcji. To transkrypcja wydaje się zatem częściej preferowanym bodźcem. Wypowiedzi kilku badanych sugerują, że wyniki te można interpretować w świetle preferencji co do modalności sensorycznych w przyswajaniu i przetwarzaniu 
informacji. Można zatem założyć, że tłumacze z dominacją wzrokową będą preferować tekst pisany, podczas gdy w przypadku słuchowców bardziej efektywne będzie nagranie jako bodziec stymulujący pamięć. Wyniki te wskazują na nowy aspekt doboru bodźca, niebrany dotąd po uwagę w projektowaniu badań z użyciem metody retrospekcji, który może się okazać kluczowy w badaniu procesu tłumaczenia.

\section{Literatura}

Bartłomiejczyk M., 2006, Strategies of simultaneous interpreting and directionality, "Interpreting. International Journal of Research and Practice in Interpreting", $8(2)$, s. $149-174$.

Brzeziński J. (2008), Badania eksperymentalne w psychologii i pedagogice, Warszawa.

Büttner O., Silberer G., 2008, Video-cued thought protocols: A method for tracing cognitive processes at the point of purchase, [w:] Brick \& Mortar Shopping in the 21st Century, T. Lowry (red.), Mahwah, NJ, s. 221-241.

Chang C., Schallert D., 2007, The impact of directionality on Chinese/English simultaneous interpreting, ,Interpreting. International Journal of Research and Practice in Interpreting", 9(2), s. 137-176.

Englund Dimitrova B., Tiselius E., 2009, Exploring retrospection as a research method for studying the translation process and the interpreting process, [w:] Methodology, Technology and Innovation in Translation Process Research, I.M. Mees, F. Alves, S. Göpferich (red.), Copenhagen, s. 109-134.

Englund Dimitrova B., Tiselius E., 2014, Retrospection in interpreting and translation: Explaining the process?, „Monti”. Special Issue - Minding Translation, 1, s. 177-200.

Ericsson K.A., Simon H.A., 1980, Verbal reports as data, „Psychological Review”, 87(3), s. 215-251.

Ericsson K.A., Simon H.A., 1993, Protocol Analysis: Verbal Reports as Data, Cambridge MA.

Ferreira A., Gottardo A., Schwieter J.W., 2018, Decision-making processes in direct and inverse translation through retrospective protocols, ,,Translation, Cognition \& Behaviour", 1(1), s. 98-118.

Gile D., 2009, Basic Concepts and Models for Interpreter and Translator Training, Amsterdam.

Gumul E., 2012, Tłumacz o ograniczeniach. Z uwag retrospektywnych tłumaczy symultanicznych, [w:] Z zagadnień dydaktyki tłumaczenia ustnego 2. Stare problemy, nowe metody, P. Janikowski (red.), Częstochowa, s. 91-116. 
Gumul E., 2017, Explicitation in Simultaneous Interpreting. A Study into Explicitating Behaviour of Trainee Interpreters, Katowice.

Gumul E., 2019, O metodzie protokołów retrospektywnych w badaniach nad tłumaczeniem symultanicznym, „Rocznik Przekładoznawczy. Studia nad Teorią, Dydaktyką i Praktyką Przekładu”, 14, s. 171-192.

Gumul E., 2020a, Retrospective protocols in simultaneous interpreting - testing the effect of retrieval cues, „Linguistica Antverpiensia. New Series - Themes in Translation Studies", 19, s. 152-171.

Gumul E., 2020b, O metodzie badawczej zapożyczonej z psychologii, czyli jak zaprojektować i przeprowadzić badanie za pomocą metody protokołów retrospektywnych w tłumaczeniu symultanicznym, „Między Oryginałem a Przekładem”, 4(50), s. 31-54.

Gumul E., 2021, Explicitation and cognitive load in simultaneous interpreting: Product- and process-oriented analysis of trainee interpreters' outputs, „Interpreting. International Journal of Research and Practice in Interpreting", 23(1), s. 45-75.

Herring R., 2018, 'I could only think about what I was doing, and that was a lot to think about': Online self-regulation in dialogue interpreting, niepublikowana praca doktorska, University of Geneva.

Herring R.E., Tiselius E., 2020, Making the most of retrospective process tracing in dialogue interpreting research, „FITISPOS International Journal”, 7(1), s. 53-71. Hild A., 2015, Discourse comprehension in simultaneous interpreting: The role of expertise and information redundancy, [w: Psycholinguistic and Cognitive Inquiries into Translation and Interpreting, A. Ferreira, J.W. Schwieter (red.), Amsterdam-Philadelphia, s. 67-100.

Ivanova A., 1999, Discourse Processing During Simultaneous Interpreting: An Expertise Approach, niepublikowana praca doktorska, University of Cambridge. Ivanova A., 2000, The use of retrospection in research on simultaneous interpreting, [w:] Tapping and Mapping the Processes of Translation and Interpreting: Outlooks on Empirical Research, S. Tirkkonen-Condit, R. Jääskeläinen (red.), Amsterdam-Philadelphia, s. 27-52.

Kohn K., Kalina S., 1996, The strategic dimension of interpreting, „Meta”, 41(1), s. $118-138$.

Liontou V., 2011, Strategies in German-to-Greek Simultaneous Interpreting: A Corpus-Based Approach, „Gramma: Journal of Theory and Criticism”, 19, s. 37-56. Mead P., 2002, Exploring hesitations in consecutive interpreting: An empirical study, [w:] Interpreting in the 21st Century: Challenges and Opportunities, G. Garzone, M. Viezzi (red.), Amsterdam, s. 73-82.

Monacelli C., 2000, Mediating castles in the air: Epistemological issues in interpreting studies, [w:] Intercultural Faultlines: Research Models in Translation Studies I: Textual and Cognitive Aspects, M. Olohan (red.), Manchester, s. 193-214. 
Napier J., 2002, Sign Language Interpreting: Linguistic Coping Strategies, Coleford, UK.

Napier J., 2004, Interpreting omissions: A new perspective, „Interpreting. International Journal of Research and Practice in Interpreting", 6(2), s. 117-142.

Napier J., Barker R., 2004, Sign Language Interpreting: The Relationship between Metalinguistic Awareness and the Production of Interpreting Omissions, „, Sign Language Studies", 4(4), s. 369-393.

Russell D., Winston B., 2014, Tapping into the interpreting process: Using participant reports to inform the interpreting process in educational settings, „Translation \& Interpreting", 6(1), s. 102-127.

Shamy M., de Pedro Ricoy R., 2017, Retrospective protocols: Tapping into the minds of interpreting trainees, „Translation \& Interpreting”, 9(1), s. 51-71.

Silva I.A.L. da, 2015, On a more robust approach to triangulating retrospective protocols and key logging in Translation Process Research, [w:] Psycholinguistic and cognitive inquiries into translation and interpreting, A. Ferreira, J.W. Schwieter (red.), Amsterdam, s. 115-175.

Tang F., 2018, Explicitation in Consecutive Interpreting, Amsterdam-Philadelphia. Tiselius E., Jenset G.B., 2011, Process and product in simultaneous interpreting: What they tell us about experience and expertise, [w:] Methods and Strategies of Process Research: Integrative Approaches in Translation Studies, C. Alvstad, A. Hild, E. Tiselius (red.), Amsterdam-Philadelphia, s. 269-300.

Vik-Tuovinen G.-V., 2002, Retrospection as a method of studying the process of simultaneous interpreting, [w:] Interpreting in the 21st Century: Challenges and Opportunities, G. Garzone, M. Viezzi (red.), Amsterdam-Philadelphia, s. 63-71.

\section{The role of cueing stimulus during retrospection as perceived by simultaneous interpreters}

\section{Summary}

The present article aims to investigate simultaneous interpreting trainees' perception of the cueing stimuli used in research adopting the method of retrospection. The survey research whose results are described in this article is a part of the experimental study (Gumul 2020a) oriented at testing the impact of two types of cues stimulating the interpreters' memory during retrospection (transcript of the source text and recording of the target text) on the informativeness and accuracy of the reports as well as the verbosity of the participants. The present article reports in more detail on the part of the study in which the participants were administered a questionnaire testing their perception of the cueing stimuli. The survey focused on the difficulty 
level of the recall, the usefulness of the cueing stimuli, and the factors facilitating retrospection. The participants were also asked to what extent they perceived a given cueing stimulus as distorting their actual memories. The results of the survey show slightly more disparity between the two types of cueing stimuli than the measurable parameters of informativeness, accuracy, and verbosity. Both groups of participants (group A exposed to the transcription of the source text and group B exposed to the recording of the target text) show slight preference for transcription as a cueing stimulus. Additional comments provided by two participants from experimental group B imply that this finding could possibly be interpreted in the context of the interpreters' sensory preference for information processing. For those with visual dominance transcription could be more effective, while those displaying auditory dominance could possibly benefit more from the recording.

Keywords: retrospection, simultaneous interpreting, process research, cueing stimuli, survey research

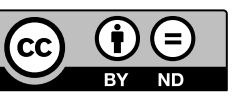

\section{Załącznik 1}

Kwestionariusz (WERSJA A):

Płeć: ............

Wiek:

Imię i nazwisko:

(TE DANE POTRZEBNE SĄ TYLKO PO TO, ABY DOPASOWAĆ KWESTIONARIUSZ DO NAGRANIA. NA ETAPIE ANALIZY DANYCH PAŃSTWA NAGRANIA I ODPOWIEDZI SĄ ANONIMIZOWANE)

1. Czy trudno było Panu/Pani przypomnieć sobie podczas retrospekcji decyzje podjęte $\mathrm{w}$ trakcie tłumaczenia?

Proszę ocenić stopień trudności w skali od 1 (łatwo) do 5 (bardzo trudno)

1. Łatwo $\square$

2. Dość łatwo

3. Ani łatwo, ani trudno $\square$

4. Trudno $\square$

5. Bardzo trudno $\square$

Komentarz: 
2. Jeśli w poprzednim pytaniu zaznaczył/a Pan/Pani opcję 4 lub 5, proszę napisać, co sprawiło, że trudno było Panu/Pani przypomnieć sobie decyzje podjęte w trakcie tłumaczenia.

Komentarz:

3. Co ułatwiło przypomnienie sobie decyzji podjętych $\mathrm{w}$ trakcie tłumaczenia?

Komentarz:

4. Co jeszcze mogłoby ułatwić przypomnienie sobie decyzji podjętych w trakcie tłumaczenia?

Komentarz:

5. Na ile pomocna w retrospekcji była transkrypcja tekstu wyjściowego? $\mathrm{Na}$ ile transkrypcja pomogła Państwu przypomnieć sobie decyzje podjęte w trakcie tłumaczenia?

Proszę ocenić stopień użyteczności tego bodźca w skali od 1 (bardzo pomocna) do 5 (całkowicie bezużyteczna)

1. Bardzo pomocna $\square$

2. Pomocna $\square$

3. Dość pomocna $\square$

4. Bez znaczenia $\square$

5. Całkowicie bezużyteczna $\square$

Dlaczego?

6. Czy wysłuchanie nagrania własnego tłumaczenia byłoby bardziej pomocne?

Proszę ocenić stopień potencjalnej użyteczności tego bodźca w skali od 1 (bardzo pomocne) do 5 (całkowicie bezużyteczne)

1. Bardzo pomocne $\square$

2. Pomocne

3. Dość pomocne $\square$

4. Bez znaczenia $\square$

5. Całkowicie bezużyteczne

Dlaczego?

7. Czy sądzi Pan/Pani, że rodzaj bodźca (transkrypcja) zniekształca zapamiętane decyzje? Czy transkrypcja powoduje, że trudno Panu/Pani rozróżnić to, co pamiętają Państwo, od wniosków wyciągniętych na podstawie przeczytania transkrypcji?

Proszę ocenić stopień zniekształcenia wspomnień w skali od 1 (w ogóle nie zniekształca) do 4 (bardzo zniekształca) 
1. W ogóle nie zniekształca, nie ma wpływu na zapamiętane decyzje $\square$

2. Zniekształca w niewielkim stopniu $\square$

3. Zniekształca $\square$

4. Bardzo zniekształca, trudno rozróżnić to, co pamiętam na temat podjętych decyzji, od wniosków wyciągniętych na podstawie przeczytania transkrypcji $\square$

Dlaczego?

\section{Załącznik 2}

Kwestionariusz (WERSJA B):

Płeć:

Wiek:

Imię i nazwisko:

(TE DANE POTRZEBNE SĄ TYLKO PO TO, ABY DOPASOWAĆ KWESTIONARIUSZ DO NAGRANIA. NA ETAPIE ANALIZY DANYCH PAŃSTWA NAGRANIA I ODPOWIEDZI SĄ ANONIMIZOWANE)

1. Czy trudno było Panu/Pani przypomnieć sobie podczas retrospekcji decyzje podjęte w trakcie tłumaczenia?

Proszę ocenić stopień trudności w skali od 1 (łatwo) do 5 (bardzo trudno)

1. Łatwo $\square$

2. Dość łatwo $\square$

3. Ani łatwo, ani trudno $\square$

4. Trudno

5. Bardzo trudno $\square$

Komentarz:

2. Jeśli w poprzednim pytaniu zaznaczył/a Pan/Pani opcję 4 lub 5, proszę napisać, co sprawiło, że trudno było Panu/Pani przypomnieć sobie decyzje podjęte $\mathrm{w}$ trakcie tłumaczenia.

Komentarz:

3. Co ułatwiło przypomnienie sobie decyzji podjętych w trakcie tłumaczenia?

Komentarz:

4. Co jeszcze mogłoby ułatwić przypomnienie sobie decyzji podjętych $\mathrm{w}$ trakcie tłumaczenia?

Komentarz: 
5. Na ile pomocne w retrospekcji było nagranie Państwa tłumaczenia? Na ile to nagranie pomogło Państwu przypomnieć sobie decyzje podjęte $\mathrm{w}$ trakcie tłumaczenia?

Proszę ocenić stopień użyteczności tego bodźca w skali od 1 (bardzo pomocne) do 5 (całkowicie bezużyteczne)

1. Bardzo pomocne

2. Pomocne

3. Dość pomocne $\square$

4. Bez znaczenia $\square$

5. Całkowicie bezużyteczne

Dlaczego?

6. Czy przeczytanie transkrypcji tekstu wyjściowego (oryginału) zamiast wysłuchania nagrania byłoby bardziej pomocne?

Proszę ocenić stopień potencjalnej użyteczności tego bodźca w skali od 1 (bardzo pomocne) do 5 (całkowicie bezużyteczne)

1. Bardzo pomocne

2. Pomocne $\square$

3. Dość pomocne

4. Bez znaczenia $\square$

5. Całkowicie bezużyteczne

Dlaczego?

7. Czy sądzi Pan/Pani, że rodzaj bodźca (nagranie własnego tłumaczenia) zniekształca zapamiętane decyzje? Czy wysłuchanie nagrania własnego tłumaczenia powoduje, że trudno Panu/Pani rozróżnić to, co pamiętają Państwo, od wniosków wyciągniętych na podstawie nagrania?

Proszę ocenić stopień zniekształcenia wspomnień w skali od 1 (w ogóle nie zniekształca) do 4 (bardzo zniekształca)

1. W ogóle nie zniekształca, nie ma wpływu na zapamiętane decyzje $\square$

2. Zniekształca w niewielkim stopniu

3. Zniekształca $\square$

4. Bardzo zniekształca, trudno rozróżnić to, co pamiętam na temat podjętych decyzji, od wniosków wyciągniętych na podstawie wysłuchania nagrania $\square$ Dlaczego? 